\title{
THE WORK OF THE VENEREAL DISEASES SCHEMES IN ENGLAND AND WALES
}

AN important proportion of our readers are interested (many of them as medical officers in Treatment Centres) in the Venereal Diseases Schemes of England and Wales, and naturally in their results. The information is always available in the Annual Reports of the Ministry of Health and of the Chief Medical Officer of the Ministry of Health, but as readers may not think of this source of information, by permission of the Controller of H.M. Stationery Office we are reprinting below the Section on Venereal Diseases in the C.M.O.'s Report for the year I935 (published December, I936).

This year's Report is particularly interesting in showing graphically the distribution of centres, with the very remarkable decrease in fresh infections with syphilis which has occurred in England and Wales in the last few years, and in discussing the question of reduction or otherwise of late effects of syphilis. The study of this section, with its tables, may at first cause the reader some disappointment that aneurysm does not seem to have been reduced. This may be due to the fact that people now live longer than they did (see the percentages in Table K), so that they have a better chance of developing this late effect of syphilis and also that there was a very great increase in syphilitic infections in this country during the years I9I4 to I920.

In the section on gonorrhœa the chief feature is a reprint of Dr. Kathleen Brown's account of the highly successful precautions taken at the Children's Medical Home, Waddon, to prevent cross-infection with gonococcal vulvo-vaginitis. This has already appeared in this Journal, but in view of its value we have judged it desirable to repeat it. The following is the Report.

To avoid any misunderstanding, it should be noted that " incidence of venereal disease" in the Report means occurrence of fresh infections.

L. W. H. 


\section{Venereal Diseases}

In the Chief Medical Officer's Annual Report for I934 reasons were given for the view that the operation of the Local Government Act of I929 had improved the efficiency of the Venereal Diseases Schemes of Local Authorities. The experience of the year I935 has reinforced this belief, since it has shown further evidence of activity on the part of Medical Officers of Health both to improve individual Venereal Disease Treatment Centres and to strengthen the links between the Venereal Disease and other branches of the Public Health Service. In this action they have continued to avail themselves of the help of the Department's advice which the Minister offered in Circular I072 dated I2th February, I930.

\section{Treatment Centres}

The number of Venereal Diseases Treatment Centres in England and Wales at the close of 1935 was 185 (including II9 conducted in voluntary hospitals); the geographical distribution was as shown in the map on p. 8I. During the year, two centres, at the Royal Southern Hospital, Liverpool, and the Royal Isle of Wight County Hospital, Ryde, were closed as it was judged that the work which they were doing could be transferred to existing centres in their vicinity without loss of efficiency and with some gain in economy. Two new centres were approved, at the Manchester Royal Eye Hospital and the Holland Sanatorium, Boston, Lincolnshire. Also, it was judged advisable now to include in the list of approved centres one (at the Salvation Army's Mothers' Hospital, London) which has dealt principally with a limited class of patients. Four centres, at Aldershot, Barnstaple, Birmingham (Aston Street) and Darlington were transferred to fresh premises.

The incidence of Venereal Disease in England AND WALES

Syphilis.-Nothing has occurred to change the view expressed in previous Reports that the annual returns of the centres afford reliable evidence of the incidence of syphilis in this country. The numbers of cases dealt 


\section{VENEREAL DISEASES SCHEMES}

with by the centres as disclosed by the returns are shown in Appendix C, Tables A to E. In the report for I934 it

MAP SHOWING INCREASES OR DECREASES IN THE NUMBERS OF RECENT (under one year)SYPHILITIC INFECTIONS DEALT WITH AT THE V.D. TREATMENT CENTRES IN ENGLAND \& WALES IN 1935 AS COMPARED WITH 1931.

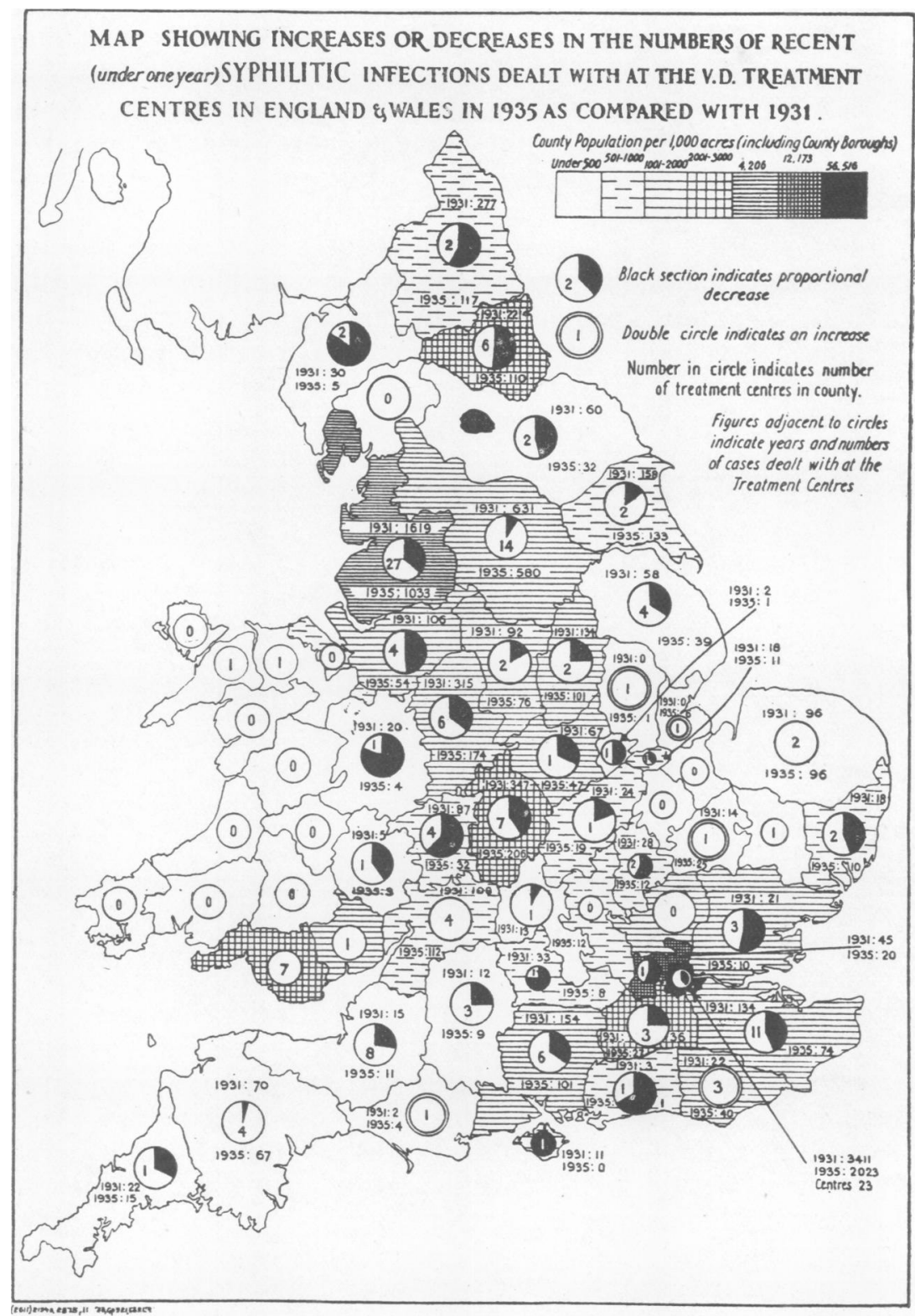

was shown that the cases of syphilis in the various stages, early and late, dealt with for the first time at the centres after rising to a maximum of 42,805 in 1920 


\section{BRITISH JOURNAL OF VENEREAL DISEASES}

had fallen to 22,010 in 1924 and had then remained more or less stationary until I 932 when a new fall had commenced, and in I934 a new low record of 20,692 had been reached. The fall continued in I935, to I9,335. The figures in Table $\mathrm{C}$ relate to cases in all stages that were dealt with for the first time at any centre. Unlike those in Table $\mathrm{A}$, they do not include any cases previously dealt with at the same or any other centre for the same infection, i.e., duplicates are excluded as far as possible. They showed in I935 a further fall, making a reduction of 4,722 cases since I930 (i.e., from I8,883 to I4,I6I). Table D shows from I93I (the first year in which these figures were collected) the cases of acquired syphilis in Table $\mathrm{C}$ with infections of less than one year's duration ; it gives therefore the best idea of the incidence of recent syphilitic infections. It records a fall of over 34 per cent. in the cases since I93I (viz.; from 9,I04 to 5,97I, the lowest figure yet recorded). The number of these cases in I935 works out at I.47 per I0,000 of the population, estimated to mid-I935, in England and Wales; calculated on a similar basis the rate in I93I was $2 \cdot 28$. The distribution of the recent infections and the changes in incidence since I93I are shown in the map.

Congenital Syphilis.-The numbers of cases of congenital syphilis dealt with at the centres since the year I930 are detailed under various age groups in Appendix C, Table E. This shows a steady fall in the numbers under each age group except that of I5 years and over. It seems unlikely that the decrease in numbers is due to more cases eluding discovery, because during the period in question there has been a steady improvement in the co-operation of the Maternity and Child Welfare and the School Medical Services with the Venereal Diseases Service in the detection and treatment of congenital syphilis. On the other hand, the co-operation between the Maternity and Child Welfare and the Venereal Diseases Services in the detection and treatment of venereal disease in pregnant women may well have been responsible for the prevention of an important amount of congenital syphilis. Other factors in the decline shown in the cases under ${ }_{5} 5$ years of age in Table $\mathrm{E}$ may be the reduction in the incidence of acquired syphilis and also greater care on the part of the infected to undergo adequate tests of cure before marrying. Evidence of 


\section{VENEREAL DISEASES SCHEMES}

steady decline in the transmission of syphilis to offspring is also contained in Table $F$, which shows deaths of infants certified as due to syphilis. The rate of $0 \cdot 29$ per I,000 live births in I935 was one-seventh of that in I9I7.

Incidence of Late Effects of Syphilis.-A question of practical interest that is often asked is what effect the Venereal Disease Scheme has had in reducing the wastage of life and efficiency caused by the late effects of syphilis. It is an important question because the greatest loss from this cause occurs in age periods (30 to 60) when people are normally of the greatest value to their families and when, therefore, death or long incapacity through sickness of the breadwinner is usually a disaster of the first magnitude. To understand this one has only to consider a few of the more important disabilities produced by syphilis. In the group of cardio-vascular diseases is syphilitic aortitis which, in the forms of aneurysm, aortic regurgitation and narrowing of orifices of coronary arteries, is responsible for long periods of invalidism and for a high percentage of the sudden deaths occurring between the ages of 30 and 6o. Of diseases of the central nervous system, the most tragic is general paralysis of the insane in which the victim frequently dissipates his fortune, possibly reducing his family to beggary before he can be certified and prevented from doing himself and others more mischief. Until a comparatively few years ago the outlook for recovery of such a case was practically hopeless, and death occurred in the majority within two years of certification. Tabes dorsalis is another important crippler of efficiency. Syphilis also takes a heavy toll of life and efficiency through causing other forms of disease which affect the nervous and circulatory systems and important organs like the liver and kidneys.

Owing to a number of complicating factors mentioned below, it is unfortunately impossible to say what, if any, effect the Venereal Disease Scheme has had in reducing the wastage from these effects of syphilis. The exact amount of damage caused by syphilis cannot be assessed, because in certificates of death from diseases of organs which are very probably due to this disease the fact of the infection is not disclosed, and in the deaths from disease of a given organ the proportion due to syphilis can only be guessed. In discussing changes in incidence 


\section{BRITISH JOURNAL OF VENEREAL DISEASES}

of the late effects of syphilis, one is therefore forced to limit the field to three diseases, general paralysis of the insane and tabes dorsalis, which are always due to syphilis, and aneurysm which is caused by it in a very high proportion of cases.

Even the question of the probable effect of the Venereal Disease Scheme on the incidence of these three diseases cannot be answered at all accurately. Deaths from general paralysis of the insane are no longer an index of the incidence of this late effect of syphilis since it has now become curable by malaria therapy and other forms of treatment; much the same qualification applies to admissions to mental hospitals. The mortality from tabes dorsalis is not a good index of incidence because, apart from the fact that this disease tends to become arrested, the extent of the influence of modern methods of treatment applied after it has declared itself is unknown. Deaths from aneurysm may then be the best index of the effect of the Venereal Disease Scheme on the incidence of late effects, but a further complicating factor is that, during the Great War, there was certainly a very large increase in the number of individuals in the country who were infected with syphilis. For example, the number of men in the British Army (as distinct from the Dominion, Colonial and Indian Forces) who were treated for syphilis in the period 4th August I9I4 to IIth November I9I8 was approximately I00,000, and between the close of the War and completion of demobilisation the incidence of venereal diseases in the Army greatly increased. A large proportion of those infected whilst serving in naval, military and air forces must have returned to homes in England and Wales, and although it is impossible to say how many would have been infected if there had been no war, it is reasonably certain that the number would have been considerably less. The increase in the incidence of syphilis in the population during the War affected both men and women. Assuming the great increase of syphilis in the period I9I4 to I920 which the above suggests, one would expect that in the absence of any counteracting factor, it would be reflected now in an increase in the incidence of such late effects as have been mentioned above.

Although it is impossible to give a clear answer to the question under discussion, it seems appropriate at this period to discuss 


\section{VENEREAL DISEASES SCHEMES}

such figures as are available ; they are presented in Appendix C, Tables $G$ to $K$, and in Graphs I and II. In Table $G$, prepared from figures kindly supplied by the Board of Control, are shown direct admissions for general paralysis of the insane to institutions for persons suffering from mental disorder in England and

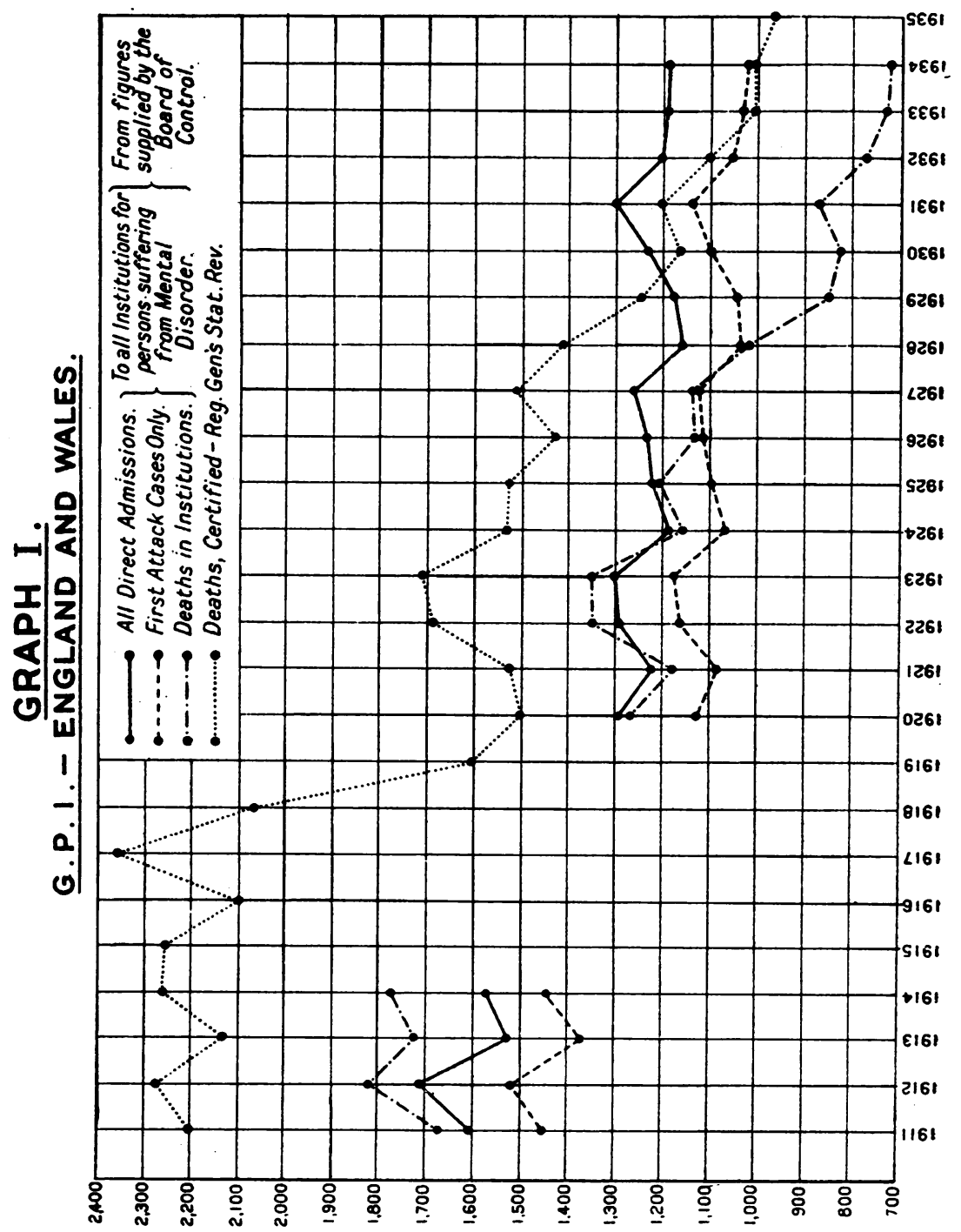

Wales and deaths from the same cause in those institutions. These do not include voluntary patients admitted prior to I93I, or those admitted to Maudsley Hospital and Hospitals and Nursing Homes approved for the reception of voluntary and temporary patients.

Table $\mathrm{H}$ shows deaths certified as due to general paralysis of 


\section{BRITISH JOURNAL •OF VENEREAL DISEASES}

the insane and tabes dorsalis, and Table $\mathrm{J}$ those from aneurysm at different age periods, as reported in the Registrar-General's Statistical Review for England and Wales. Table $\mathrm{K}$ shows the figures in Table $\mathrm{J}$ expressed as rates per million persons in the different age groups. Graph I shows admissions to institutions and deaths from general paralysis of the insane and Graph II shows the same for the sexes separately.

In regard to general paralysis of the insane the figures show

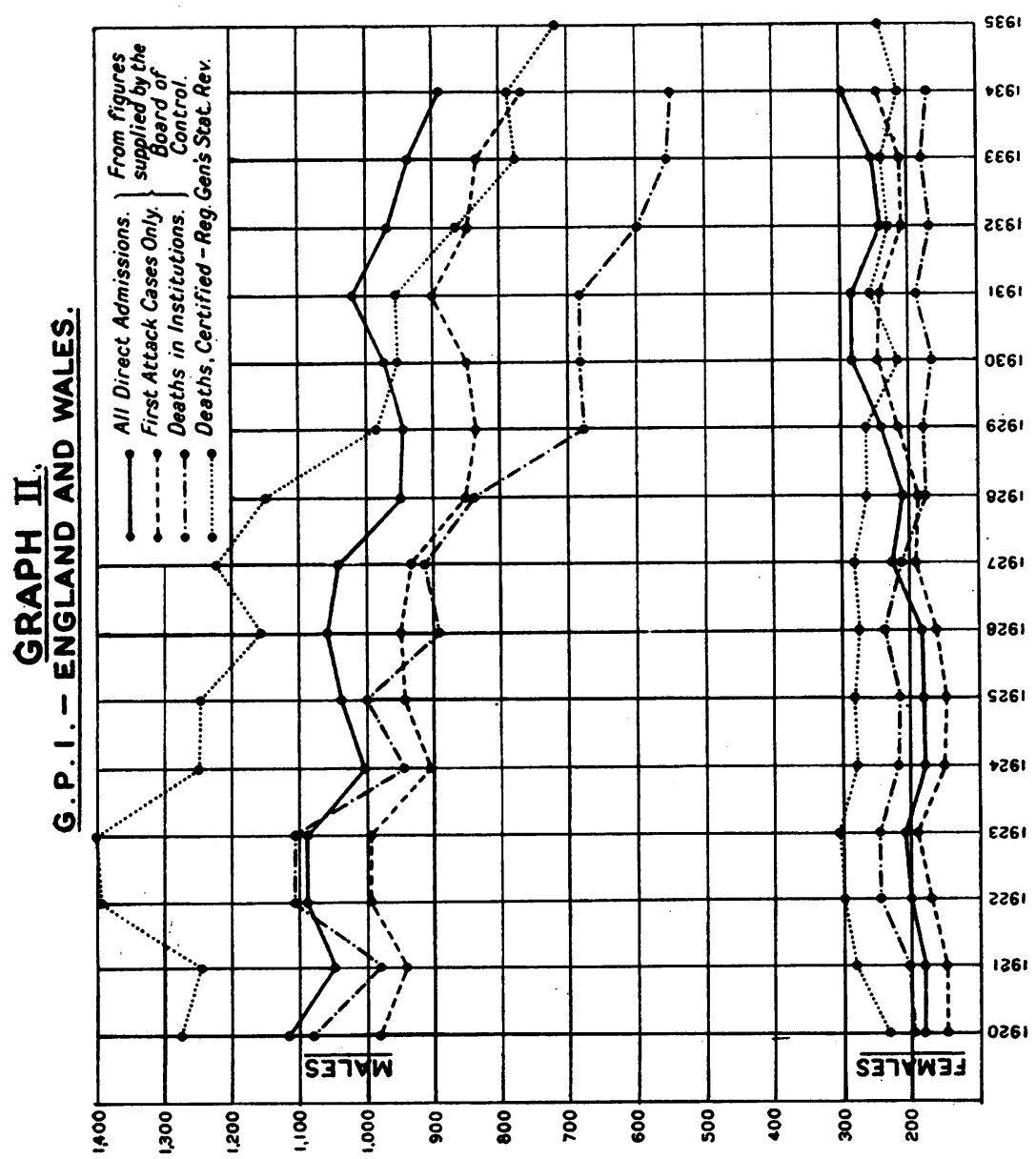

generally great reductions in both admissions and deaths. Thus in the four years I93I-34 the direct admissions were 23 to 25 per cent. fewer than in the four years IgII-I4, and the deaths were less than half.

The details show that the explanation is not easy. Thus the greater part of these declines occurred between I9I4 and I920, and the figures relating to deaths in the Registrar-General's Statistical Review show the most pronounced fall from I9I 8 to 


\section{VENEREAL DISEASES SCHEMES}

I920. It is difficult to believe that the institution of the Venereal Disease Scheme in I9I6 could have been responsible for the decline in deaths from general paralysis of the insane so soon afterwards, seeing that this effect of syphilis does not usually show itself for more than Io years after infection (Lomholt has calculated an average of 18.5 to 18.6 years), and hardly any of those who developed general paralysis between I9I 4 and I920 can have been treated by modern methods either as civilians or whilst serving in the armed forces. From I920 to I934 the figures relating to admissions to institutions show a decided increase in the case of females and a decided decrease in males (see Table G and Graph II). If direct admissions were a reliable index of incidence, it might be argued that the difference was due to men being more likely to be treated in the earlier stages of syphilis than are women because in the latter it is very common for syphilis to go undetected and untreated for many years. The difficulty in accepting this explanation is that we do not know how far direct admissions represent incidence seeing that the Graphs and Tables $\mathrm{G}$ and $\mathrm{H}$ show that a considerable number of deaths occur outside institutions, so that many cases never come under the notice of the Board of Control. Again the difference in the two sexes in regard to direct admissions might be due to some extent to more men than women being treated in the earlier stages of general paralysis in general hospitals, and, through the modern pyretic and pentavalent arsenical treatment, being restored to health before becoming certifiable. The difference in the two sexes in regard to deaths between I920 and I934 might be due to the more efficient treatment of syphilis in men than in women, but another explanation is earlier treatment of the kind that is more particularly applicable to general paralysis. From a Return furnished by the Board of Control it appears that since 1927 from 600 to 700 patients in institutions for care of persons suffering from mental disorder have been inoculated with malaria each year, and approximately a quarter of them have been discharged "improved." The figures show what a considerable part pyretic treatment must have played in the reduction of mortality from general paralysis and the impossibility of assessing the amount of general paralysis which has been prevented by the more efficient treatment of syphilis in the population for which the Venereal Disease Scheme is responsible. Deaths from tabes dorsalis have shown no very striking changes in numbers since 1920 and deaths from aneurysm show an increase, but the rates for males in the age period (30 to 60 ) when this effect of syphilis most commonly manifests itself show some fairly substantial decreases (see Table K).

Soft Chancre.-The figures under this heading show no evidence of any important increase. It is likely that any cases of Lymphogranuloma inguinale dealt with at the centres would be grouped under the heading of soft chancre because of the bubo to which it commonly gives rise. It does not appear from the figures or from enquiries 


\section{BRITISH JOURNAL OF VENEREAL DISEASES}

at the centres that the incidence of Lymphogranuloma inguinale has increased in this country.

Gonorrhoea.-The cases of gonorrhoea dealt with for the first time in I935 (Table C) showed a further decrease, and the figure relating to males was the lowest since I926.

\section{OUtBREaks of Gonococcal Vulvo-vaginitis}

From time to time considerable trouble is caused in one institution or another by an outbreak of gonococcal vulvo-vaginitis in the female children there. The disease is a very intractable one, often resisting the most careful treatment for many months, and during this time it is a source of great distress to the patients and their parents or guardians, not only because of its physical effects but because of the social stigma which such an infection always carries. The fact that such outbreaks still occur in institutions where careful precautions against them are taken as a matter of routine, seems to call for a review of the defences usually set up against it to see if there is any gap in them which could usefully be closed. Investigation of such an outbreak usually discloses that on a certain day a female child, who may have been in the ward for several weeks, was found to be suffering from a purulent vaginal discharge containing gonococci and that an examination of the other children undertaken at once in consequence of this discovery revealed the disturbing fact that some of these were also infected. It is important to note that in some cases the signs of the disease that were visible to the naked eye have been practically nil, the fact of the infection being revealed only by microscopical or cultural examination of secretions from the vagina or rectum or both. Often, also, in spite of the children first discovered to be infected having been isolated, other female children in the same ward have become infected at a later date. This suggests that, as the disease is not air or insect-borne but conveyed either by direct contagion or through the medium of contaminated fingers or articles, a living source of infection has eluded detection. The fact that the germ is a comparatively delicate one, being killed by drying, suggests that the contamination of fingers or articles responsible for the spread of the disease was probably quite recent. 


\section{VENEREAL DISEASES SCHEMES}

In some of the institutions where these outbreaks have occurred every child had been carefully examined for vulvo-vaginitis, specimens of secretion taken for laboratory examination on admission, and the child isolated for some days before being allowed to mix with the others ; in spite of these precautions infection occurred. Sometimes a nurse has been suspected, and this may have been the cause of some outbreaks, but in others the attendants have been proved to be quite healthy. The solution of the problem in most cases is probably contained in the fact that a child suffering from gonococcal vulvo-vaginitis may show no sign of the disease on ordinary inspection, no gonococci may be found in specimens of vaginal secretion taken repeatedly over a period of some weeks, and then a relapse may occur with a discharge which, without being very obvious, can contaminate fingers and such articles as may be brought into contact with the external genital organs of other children in the ward. It follows, therefore, that the only course of safety lies in a régime based on the principle that every female child, whatever signs she may present, is possibly a sufferer from gonorrhœal vulvo-vaginitis, or proctitis, or both, and that on no account must secretions from her uro-genital or anal canal be allowed to come into contact with the external genitals of any other child, whether directly or through the medium of fingers, towels and the like. That precautions ensuring absolute isolation of child from child in this respect are practicable is shown by the experience of the Children's Home, Coldharbour House, Waddon. This Home is for the reception and care of children suffering from vulvovaginitis and it also admits a certain number of female children not suffering from vulvo-vaginitis but from congenital syphilis. The latter children, as well as those who are believed to be cured of the vulvo-vaginitis and are being retained in the Home only for tests of cure, sleep in the same dormitories as the children with active vulvo-vaginitis, play and eat with them and are in fact isolated from them only in the ways shown in the following extract, kindly revised by the author, from a paper which was read by the Medical Officer of the Home, Dr. D. Kathleen Brown,* before the members of the Medical Society for the Study of Venereal Diseases.

* Brit. Jour. Ven. Dis., 1935, XI, 207. 


\section{BRITISH JOURNAL OF VENEREAL DISEASES}

That these precautions are successful is proved by the fact that in the 16 years the Home has been in existence no child admitted for the treatment of congenital syphilis has ever acquired gonorrhœa.

\section{Children's Medical Home, Waddon}

"The special precautions adopted in the Home to prevent cross-infection of congenital syphilitic cases and reinfection of gonococcal cases are very rigid and are adhered to most strictly. They may be summed up as follows :-

(I) All cases admitted with acute infection and profuse purulent discharge are kept in bed until the acute inflammation has subsided and the discharge has lessened. Rest in bed is not necessary in subacute or chronic cases, as a rule.

(2) No child is ever allowed in or on another child's bed.

(3) Each child is provided with her own flannel and bath towel upstairs, which are kept hanging on the back of her locker.

(4) Each child has her own face flannel, towel, tooth brush, and marked bag containing tooth paste, hair brush and comb, hanging on a peg marked with a letter or number over the basins in the wash-room downstairs.

(5) There are no lavatories in the Home for the children. Each child has her own chamber upstairs which is kept under her bed, and a second one downstairs which is kept in a special stand of pigeon holes, each marked with a letter or number in one part of the wash-room. Here there are several separate cubicles where the chambers can be used privately. At the further end is a sluice sink.

(6) The children are taught to wash their hands after defæcation and micturition. The children's nurse or nursery maid is always on duty in the wash-room morning and evening. Whenever she attends to any child she always washes her hands afterwards.

(7) The children's nurse or nursery maid wears a special overall and gloves for bathing the children. Faces are always washed in the basins downstairs and never in the bath. No small child is ever washed or dried sitting on the lap, but always in the bath.

(8) Baths are thoroughly swabbed with Lysol ( $\mathrm{I}$ in 3) and cleaned immediately after use in the case of every child in the Home.

(9) Mattresses are all covered with large rubber sheets and are not stoved between cases as a routine. Blankets are stoved and washed between cases.

(Io) Sheets, pillow cases and towels are put straight into a copper of ' persil' solution and boiled for not less than half an hour. Knickers and nightgowns are soaked in weak Lysol ( $I$ in 5o) before washing, and all except woollen ones 


\section{VENEREAL DISEASES SCHEMES}

are boiled. Vests and overalls are washed with carbolic soap.

(II) Clothes taken off at night are put on a chair by the child's bed. The nightdress is kept in a bag hanging on the side of the locker during the day, dressing-gown in the locker and slippers under the bed. Outdoor coats and hats are kept on marked pegs in the children's hall.

(12) Toys, dolls, etc., used upstairs are kept on the owner's bed or in her locker. They are kept separate and not shared with another child. The toys used downstairs during the day-time are shared in common among the children.

(I3) All china, spoons and forks are washed and boiled in a special copper after every meal.

(I4) Temperatures are taken in the axilla as a rule, rarely in the mouth, and never in the groin or rectum.

(I5) The precautions taken in the treatment room for cleaning table, instruments, gloves, etc., are similar to those adopted in any clinic. For the treatment table small rubber sheets are used which are changed after each case and soaked in Lysol ( $\mathrm{I}$ in 40 ) for at least twenty minutes before being thoroughly dried."

\section{Testing of new Remedies for the Treatment of Venereal Diseases}

Periodically, new drugs are put forward by manufacturers as improvements on those now used for the treatment of venereal diseases, and in some cases, especially with those suggested for treatment of syphilis, it becomes necessary that they should be tested clinically before being put on the market. Since the clinical trial of such remedies is likely to be completed more speedily and reliably in a number of centres than in one, a subcommittee of the Therapeutic Trials Committee of the Medical Research Council has been formed for the purpose of arranging the details of any trials that may be necessary and of carrying them out. The sub-committee is under the Chairmanship of Dr. T. Carnwath, Deputy to the Chief Medical Officer of the Ministry, and its members are Col. L. W. Harrison, a Medical Officer of the Ministry, Lt.-Col. E. T. Burke, Dr. T. Anwyl Davies, Dr. V. E. Lloyd, Dr. G. L. M. McElligott and Dr. M. Rorke, Directors of the Whitechapel Clinic and of the Venereal Disease Treatment Centres at St. Thomas's, Guy's, St. Mary's and the Royal Free Hospitals, respectively. The sub-committee has already carried out tests of a number of drugs that have been recommended for the treatment of syphilis. 


\section{BRITISH JOURNAL OF VENEREAL DISEASES}

\section{Laboratory Assistance in the Diagnosis of VeNEREAL Disease}

Table $\mathrm{L}$ in Appendix $\mathrm{C}$ shows under different headings the numbers of examinations of pathological specimens carried out under the Venereal Disease Scheme in the approved laboratories and in the centres. The total was $7 \mathrm{I} 2,406$, an increase of $36,68 \mathrm{I}$ over the number in I934. It includes 538,532 carried out for the treatment ccntres (79,970 in the centres themselves) and I73,874 " for practitioners," that is, of specimens from patients of private practitioners and of medical officers of hospitals and institutions other than Venereal Disease Treatment Centres. The returns do not distinguish between specimens from private patients and from patients in institutions, but a special enquiry kindly answered by the pathologists of the approved laboratories has shown that in 1935 approximately $8 \mathrm{r} \cdot 7$ per cent. of the Wassermann tests and approximately 64.5 per cent. of the microscopical tests for $S$. pallida and gonococci entered under the heading "for practitioners " were on specimens from patients in institutions. In an important proportion of these the specimens were taken as a preliminary to referring the patient to some Venereal Disease Treatment Centre, and in many others they were sent by medical officers of other branches of the Public Health Service such as the Maternity and Child Welfare and the School Medical Services. The details of the table show that since 1932 there has been a decrease in the total number of specimens examined for S. pallida; probably this is connected with the remarkable decrease in the incidence of recent infections which has been commented upon above.

Serum tests for syphilis continued to increase in spite of the smaller numbers of syphilis cases dealt with at the centres, and there has also been a steady increase in syphilitic serum tests other than the Wassermann test. These additional tests have for the most part been supplementary to the Wassermann test and are evidence of a growing appreciation of the fact that it is generally advantageous to test a serum for syphilis by two or more methods. The gonococcal complement fixation tests made in I935 were almost double the number done in I932, and the returns showed that the number of approved 


\section{VENEREAL DISEASES SCHEMES}

laboratories in which the test was being performed had increased to 44. Five or six years ago only four or five of the approved laboratories in this country would undertake this test. On the one hand there was little or no demand for it by clinicians outside a few Venereal Disease Treatment Centres and, on the other, certain pathologists refused to carry it out because they believed it to be unreliable. The demonstration by numerous pathologists that, when carried out with reasonable care, the test is highly specific, and the substantial improvements in technique introduced by I. N. O. Price first at the St. Thomas's Hospital Clinic and later at the Whitechapel Clinic have gone far to overcome a certain prejudice against it on the part of many pathologists. On the clinical side, there has been a steadily increasing appreciation of its value not only in diagnosis and tests of cure but as a gauge of the resistance to the gonococcus being acquired by the patient, and, therefore, as a guide in vaccine therapy. Cultural tests carried out by the approved laboratories have increased considerably. Practically all of them are for the diagnosis of gonorrhœea and, with the gonococcal complement fixation test, they are evidence of steady improvement in the methods of diagnosis and treatment of gonorrhœa employed in the treatment centres.

The comparisons of the different methods of the Wassermann test employed in approved laboratories with No. I Method of the Medical Research Council as modified by Wyler * have been continued and, by the end of I935, I 28 had been completed. The method employed as standard in these comparisons has, itself, been compared in three international laboratory conferences with a number of others, and in two was found to be the most satisfactory of the Wassermann tests, while in the third it shared this position with another method. Generally it has been found, both in the international and the national comparisons, that methods which have afforded higher percentages of positive reactions with syphilitic sera have given also positive reactions with non-syphilitic. The procedure in a comparison of this method with that employed in an approved laboratory is to send to the collaborating pathologist in weekly batches a series of 200 specimens of serum obtained from the Venereal

* Medical Research Council, Special Report Series, No. I29. 


\section{BRITISH JOURNAL OF VENEREAL DISEASES}

Disease Treatment Centre at St. Thomas's Hospital. As nearly as possible simultaneously the same sera are tested by Dr. Wyler in the Ministry's laboratory, using the No. I Method mentioned above. The results are sent to the Ministry of Health, and until they have been received the clinical data are withheld from both testers. When the tests of the 200 specimens have been completed both sets of results, with the clinical data and a summary, are sent to both laboratories. The opportunity thus afforded of comparing their methods with one of proved reliability on series of unknown sera has been generally welcomed by pathologists, and the results have at different times led to considerable improvements in individual methods.

\section{Revision of the Transfer Card (Form V I5)}

The revision of the Personal Card carried by seamen receiving treatment for venereal disease under the Brussels Agreement, which was mentioned in this Report for I934, has been followed by a similar revision of the card, Form V $\mathrm{I}_{5}$, used by patients who have to obtain their treatment at more than one venereal diseases treatment centre in this country. The new card, Form V I5 (revised), was issued by the Minister in October I935. It is hoped that by the use of the new form the particulars of a patient's case will be transmitted from one Venereal Disease Officer to another more intelligibly and easily than in the past.

Brussels Agreement.-In this Report for 1934 it was mentioned that the Office International d'Hygiene publique was studying the problem of making arrangements to ensure a greater regularity of anti-syphilitic treatment of merchant seamen. At the same time the view was expressed that possibly the recent publication of the Report on the treatment of early syphilis by the Committee of Experts on Syphilis and Cognate Subjects convened by the Health Organisation of the League of Nations would help the solution of this important problem. The Office has now addressed to the different Governments adhering to the Brussels Agreement a communication containing a number of recommendations on the planning of courses of treatment for merchant seamen. This communication was forwarded by the 


\section{VENEREAL DISEASES SCHEMES}

Ministry on I6th April I936 to all Councils of Counties and County Boroughs and the Common Council of the City of London, with a revised List $7 a$ (showing centres in ports at home and abroad where seamen can obtain treatment) and an explanatory Circular, 1536. As was expected, the recommendations of the Office are based on those by the Committee of Experts mentioned above, and while there is no question of forcing on Medical Officers the adoption in any particular case of any rigid schedule of treatment, it is hoped that if all Centres adopt the Committee's schedules as a common basis on which to frame their individual schemes of treatment for seamen, this important section of the infected will be dealt with far more effectively than in the past. It is hardly necessary to impress on Medical Officers of Venereal Disease Treatment Centres the importance of their supporting actively this effort to improve the treatment of merchant seamen suffering from syphilis. Irregular and insufficient anti-syphilitic treatment not only affects the individual adversely but also favours the spread of syphilis in the community, and importation of syphilis by merchant seamen is an important factor in maintaining the incidence of the disease in any country. 


\section{BRITISH JOURNAL OF VENEREAL DISEASES}

\section{APPENDIX C}

England and Wales: Tables relating to Venereal Diseases

\section{TABLE A}

\begin{tabular}{|c|c|c|c|c|c|c|c|c|}
\hline \multirow{2}{*}{ Year } & \multicolumn{6}{|c|}{$\begin{array}{c}\text { Number of cases dealt with for the first time at the } \\
\text { Treatment Centres }\end{array}$} & \multirow{2}{*}{$\begin{array}{c}\text { Total } \\
\text { number of } \\
\text { attendances }\end{array}$} & \multirow{2}{*}{$\begin{array}{l}\text { Number of } \\
\text { Treatment } \\
\text { Centres at } \\
\text { end of } \\
\text { year }\end{array}$} \\
\hline & Syphilis & $\begin{array}{c}\text { Soft } \\
\text { chancre }\end{array}$ & Gonorrhœa & $\begin{array}{l}\text { Total } \\
\text { V.D. }\end{array}$ & $\begin{array}{c}\text { Other } \\
\text { than } \\
\text { V.D. }\end{array}$ & Total & & \\
\hline I9I7 & - & - & $\longrightarrow$ & - & 一 & 29,036 & 204,692 & I I 3 \\
\hline I9I 8 & 26,912 & 806 & I 7,635 & 45,353 & 6,622 & $5 \mathrm{I}, 975$ & 488, I 37 & I34 \\
\hline 1919 & 42,134 & 2,164 & 38,499 & 82,797 & I 5,447 & 98,244 & $I, 002,79 I$ & 160 \\
\hline I920 & 42,805 & 2,442 & 40,284 & $85,53 \mathrm{I}$ & I9,654 & 105,185 & $\mathrm{I}, 4^{88,5} 5^{\mathrm{I}}$ & I90 \\
\hline I92I & 32,733 & I, 654 & 32,433 & 66,820 & I 7,459 & 84,279 & I,6I2,592 & I94 \\
\hline I922 & 25,762 & I, 108 & 29,477 & 56,347 & I6,988 & 73,335 & $I, 560,568$ & I9I \\
\hline I923 & 23,927 & I, I IO & 30,908 & 55,945 & I 7,668 & 73,613 & $\mathrm{I}, 60_{5}, 6 \mathrm{I} 7$ & 192 \\
\hline 1924 & 22,010 & I, 098 & 31,272 & 54,380 & I $8,84^{2}$ & 73,222 & I, 645,4 I 5 & I93 \\
\hline I925 & $22,5^{88}$ & I, 106 & 33,463 & $57, \mathrm{I}_{57}$ & 21,053 & 78,210 & $1,719,1_{4}^{8}$ & I93 \\
\hline I926 & $22,55^{\circ}$ & I, I $5^{\circ}$ & 35,052 & $5^{8,75^{2}}$ & 22,754 & $8 \mathrm{I}, 506$ & $2,008,063$ & I90 \\
\hline I927 & 23,395 & 1,063 & $3^{8,242}$ & 62,700 & 25,436 & 88,136 & $2,179,707$ & I86 \\
\hline I928 & 22,761 & I, I38 & 42,032 & 65,931 & 28,029 & 93,960 & $2,422,749$ & I88 \\
\hline I929 & 22,019 & I, 298 & 44,166 & $67,4^{8} 3$ & 27,980 & $95,4^{6} 3$ & $2,604,2$ I 7 & I 88 \\
\hline $193^{\circ}$ & 23,120 & $I, 324$ & 45,001 & 69,445 & 31,104 & IOO, 549 & $2,817,195$ & 190 \\
\hline I93I & 22,934 & $I, I 63$ & 42,460 & 66,557 & $3 \mathrm{I}, 82 \mathrm{I}$ & 98,378 & $2,992,761$ & 189 \\
\hline 1932 & 22,215 & 952 & $4 \mathrm{I}, 25 \mathrm{I}$ & 64,4 I 8 & 32,997 & 97,4 I 5 & 3,109, I 74 & I 88 \\
\hline I933 & 21,525 & 926 & 43,226 & 65,677 & 32,767 & 98,444 & $3,252,323$ & I 86 \\
\hline I934 & 20,692 & 960 & 43,391 & 65,043 & $36,31 \mathrm{I}$ & IOI, 354 & $3,407,000$ & I84 \\
\hline I935 & I9,335 & I , I I 2 & 41,332 & $6 \mathrm{I}, 779$ & 36,230 & 98,009 & $3,398,678$ & I 85 \\
\hline
\end{tabular}

* Includes cases transferred from centre to centre and cases that returned after being struck off the books in previous years.

\section{TABLE B.-Attendances per Current Case}

\begin{tabular}{|c|c|c|c|c|}
\hline \multirow{2}{*}{ Year } & \multicolumn{2}{|c|}{ Syphilis } & \multicolumn{2}{|c|}{ Gonorrhœa } \\
\hline & Males & Females & Males & Females \\
\hline I923 & $6 \cdot 8$ & $7 \cdot 3$ & I5.7 & I 5.5 \\
\hline 1928 & $9 \cdot I$ & $9 \cdot 3$ & $24 \cdot 0$ & I $8 \cdot I$ \\
\hline 1929 & $9 \cdot 5$ & $9 \cdot 2$ & $24 \cdot 5$ & $17 \cdot 7$ \\
\hline 1930 & $9 \cdot 8$ & $9 \cdot 7$ & $26 \cdot 5$ & $18 \cdot 0$ \\
\hline I93I & $10 \cdot 7$ & I I $\cdot 0$ & $29 \cdot 0$ & $20 \cdot 4$ \\
\hline 1932 & I I 99 & $12 \cdot 0$ & $3^{I} \cdot 7$ & $2 \mathrm{I} \cdot 4$ \\
\hline I933 & $12 \cdot 2$ & I $2 \cdot 5$ & $32 \cdot 2$ & 23.5 \\
\hline I934 & $12 \cdot 4$ & I3.I & $34^{\circ} 0$ & $25 \cdot 9$ \\
\hline I935 & $12 \cdot 9$ & I $3 \cdot 6$ & $34^{\circ} 9$ & $26 \cdot 5$ \\
\hline
\end{tabular}




\section{VENEREAL DISEASES SCHEMES}

TABLE C.-Number of Cases dealt with for the first time at any Centre*

\begin{tabular}{|c|c|c|c|c|c|c|c|}
\hline \multicolumn{4}{|c|}{ Year } & Syphilis & Soft chancre & Gonorrhœa & Total V.D. \\
\hline 恣 & $\begin{array}{l}1925 \\
1926 \\
1927 \\
1928 \\
1929 \\
1930 \\
1931 \\
1932 \\
1933 \\
1934 \\
1935\end{array}$ & $\begin{array}{l}\cdot \\
. \\
. \\
. \\
. \\
. \\
. \\
. \\
. \\
.\end{array}$ & $\begin{array}{l}\dot{.} \\
\dot{.} \\
\dot{.} \\
\dot{.} \\
\dot{.} \\
\dot{.} \\
\dot{.}\end{array}$ & $\begin{array}{r}\text { I I , } 782 \\
\text { I } 2, \text { I } 18 \\
\text { I } 2,393 \\
\text { I } 2,05 \text { I } \\
\text { I I , 538 } \\
\text { I I,967 } \\
\text { I } 1,285 \\
\text { I I }, 032 \\
\text { I0,738 } \\
9,6 \text { I } 5 \\
8,596\end{array}$ & $\begin{array}{r}\mathrm{I}, 048 \\
\mathrm{I}, 070 \\
986 \\
\mathrm{I}, 053 \\
\mathrm{I}, 202 \\
\mathrm{I}, 244 \\
\mathrm{I}, 042 \\
845 \\
826 \\
876 \\
\mathrm{I}, \mathrm{OI} \mathbf{I}\end{array}$ & $\begin{array}{l}24,398 \\
25,535 \\
28,195 \\
30,425 \\
31,810 \\
32,217 \\
29,310 \\
28,179 \\
29,169 \\
28,787 \\
27,506\end{array}$ & $\begin{array}{l}37,228 \\
38,723 \\
41,574 \\
43,529 \\
44,550 \\
45,428 \\
41,637 \\
40,056 \\
40,733 \\
39,278 \\
37,113\end{array}$ \\
\hline 离 & $\begin{array}{l}1925 \\
1926 \\
1927 \\
1928 \\
1929 \\
1930 \\
1931 \\
1932 \\
1933 \\
1934 \\
1935\end{array}$ & 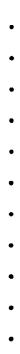 & 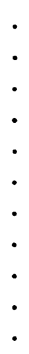 & $\begin{array}{l}7,385 \\
7,133 \\
7,553 \\
7,090 \\
6,586 \\
6,916 \\
6,827 \\
6,461 \\
6,029 \\
5,838 \\
5,565\end{array}$ & $\begin{array}{l}27 \\
21 \\
20 \\
28 \\
22 \\
17 \\
20 \\
29 \\
22 \\
10 \\
16\end{array}$ & $\begin{array}{l}6,120 \\
6,416 \\
6,809 \\
7,810 \\
7,798 \\
7,939 \\
7,697 \\
7,677 \\
8,583 \\
8,199 \\
7,732\end{array}$ & $\begin{array}{l}\text { I } 3,532 \\
\text { I } 3,570 \\
\text { I } 4,382 \\
\text { I } 4,928 \\
\text { I } 4,406 \\
\text { I } 4,872 \\
\text { I } 4,544 \\
\text { I } 4,167 \\
\text { I } 4,634 \\
\text { I } 4,047 \\
I_{3}, 313\end{array}$ \\
\hline
\end{tabular}

* Excludes cases transferred from centre to centre and those that returned with the same infections after being struck off the books in previous years.

TABle D.-Cases of Acquired Syphilis in Table C with Infections of less than One Year

\begin{tabular}{|c|c|c|c|c|c|c|c|}
\hline & \multirow{2}{*}{ Year } & & \multicolumn{2}{|c|}{ Number } & \multicolumn{2}{|c|}{ Per cent. of Table $C$ cases } & \multirow{2}{*}{$\begin{array}{l}\text { Rate per } \\
\text { Io,ooo } \\
\text { population }\end{array}$} \\
\hline & & & M. & F. & M. & F. & \\
\hline I93I & - & - & 6,421 & 2,683 & $56 \cdot 9$ & $39 \cdot 3$ & $2 \cdot 28$ \\
\hline 1932 & - & - & 6,196 & 2,532 & $56 \cdot 2$ & $39 \cdot 2$ & $2 \cdot 17$ \\
\hline 1933 & - & - & 5,949 & $2,14 \mathrm{I}$ & $55 \cdot 4$ & $35 \cdot 5$ & $2 \cdot 01$ \\
\hline 1934 & - & - & 4,888 & 2,030 & $50 \cdot 8$ & $34 \cdot 8$ & $I \cdot 7 I$ \\
\hline 1935 & - & • & 4,226 & $\mathrm{I}, 745$ & $49 \cdot 2$ & $3 I \cdot 4$ & $I \cdot 47$ \\
\hline
\end{tabular}

TABLE E.-Cases of Congenital Syphilis dealt with for the first time at the Treatment Centres

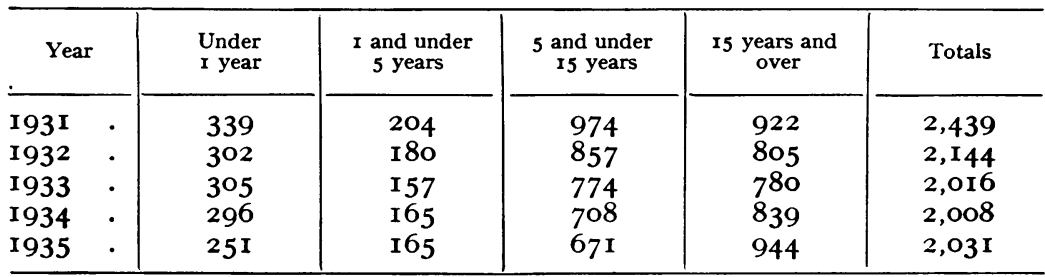




\section{BRITISH JOURNAL OF VENEREAL DISEASES}

TABLE F.-Death Rates, per I,000 Live Births, of Infants under One Year certified as due to Syphilis.-Information extracted from the Registrar-General's Statistical Revieres.

\begin{tabular}{|c|c|c|c|c|c|c|c|c|}
\hline 1912 & . & . & $I \cdot 34$ & I924 & . & & . & 0.91 \\
\hline 1913 & . & . & $I \cdot 46$ & 1925 & . & . & . & 0.82 \\
\hline 1914 & . & . & $I \cdot 55$ & 1926 & . & . & . & 0.84 \\
\hline 1915 & . & . & $I \cdot 44$ & 1927 & . & . & . & 0.77 \\
\hline 1916 & . & . & $I \cdot 57$ & 1928 & - & & . & $0.7 \mathrm{I}$ \\
\hline I9I 7 & . & . & 2.03 & 1929 & . & & . & $0 \cdot 64$ \\
\hline 1918 & . & . & $I \cdot 90$ & 1930 & . & & . & 0.55 \\
\hline 1919 & . & . & $I \cdot 76$ & I93I & • & . & . & $0.5 \mathrm{I}$ \\
\hline 1920 & . & . & $I \cdot 5 I$ & 1932 & . & & . & 0.47 \\
\hline I92I & . & . & $I \cdot 43$ & 1933 & . & & & 0.40 \\
\hline 1922 & $\cdot$ & . & $I \cdot I 2$ & 1934 & . & & & $0 \cdot 34$ \\
\hline 1923 & . & . & I.05 & I935 & . & & . & 0.29 \\
\hline
\end{tabular}

Table G.-General Paralysis of the Insane.

Direct admissions to, and deaths in, institutions for persons suffering from mental disorder in England and Wales. (Does not include voluntary patients admitted prior to I93I, or those admitted to Maudsley Hospital and Hospitals and Nursing Homes approved for the reception of Voluntary and Temporary Patients.)-Information received from Board of Control.

\begin{tabular}{|c|c|c|c|c|c|c|c|c|c|}
\hline \multirow{2}{*}{ Year } & \multicolumn{3}{|c|}{$\begin{array}{l}\text { All direct admissions } \\
\text { for G.P.I. }\end{array}$} & \multicolumn{3}{|c|}{$\begin{array}{l}\text { Direct admissions of first } \\
\text { attack cases of G.P.I. }\end{array}$} & \multicolumn{3}{|c|}{ Deaths from G.P.I. } \\
\hline & M. & F. & Total & M. & F. & Total & M. & F. & Total \\
\hline I9I I & $I, 362$ & 254 & I,6I6 & 1,237 & 224 & $\mathrm{I}, 46 \mathrm{I}$ & 1,360 & 325 & I,685 \\
\hline 1912 & $I, 433$ & $28 I$ & $I, 7 I 4$ & I, 285 & $24 \mathrm{I}$ & 1,526 & I, 457 & 367 & $I, 824$ \\
\hline 1913 & $I, 285$ & 247 & $\mathrm{I}, 532$ & $\mathrm{I}, \mathrm{I} 60$ & 214 & $\mathrm{I}, 374$ & I, 404 & 320 & $I, 724$ \\
\hline \multirow[t]{2}{*}{ I9I4 } & $I, 365$ & 214 & $\mathbf{I}, 579$ & $\mathrm{I}, 267$ & 184 & $\mathbf{I}, 45^{\mathrm{I}}$ & $\mathrm{I}, 46 \mathrm{I}$ & 319 & 1,780 \\
\hline & \multicolumn{9}{|c|}{ Figures for 1915 to 1919 inclusive not available. } \\
\hline 1920 & $I, 116$ & I 78 & I,294 & 976 & I 54 & $\mathbf{I}, \mathbf{1} 30$ & $\mathrm{I}, 074$ & 198 & 1,272 \\
\hline 1925 & I,039 & I79 & 1,218 & 945 & I 55 & I, IOO & 1,000 & 216 & 1,216 \\
\hline 1930 & 969 & 277 & 1,246 & 854 & 247 & I,IOI & 675 & 163 & 838 \\
\hline I93I & 1,023 & 278 & 1,301 & 903 & 242 & I, I 45 & 680 & 192 & 872 \\
\hline 1932 & 966 & $24 \mathrm{I}$ & $\mathrm{I}, 207$ & 848 & 2 I I & 1,052 & 598 & 169 & 767 \\
\hline 1933 & 939 & 257 & I,196 & 832 & 210 & 1,042 & 557 & 176 & 733 \\
\hline 1934 & 894 & 298 & $\mathrm{I}, 192$ & 767 & 249 & 1,016 & 554 & I69 & 723 \\
\hline
\end{tabular}




\section{VENEREAL DISEASES SCHEMES}

Table H.-General Paralysis of the Insane and TABES DORSALIS.

Deaths and Crude Annual Death Rates per million living.-Information extracted from the Registrar-General's Statistical Reviews.

\begin{tabular}{|c|c|c|c|c|c|c|c|c|}
\hline \multirow{3}{*}{ Year } & \multicolumn{4}{|c|}{ General paralysis of the insane } & \multicolumn{4}{|c|}{ Tabes dorsalis } \\
\hline & \multicolumn{2}{|c|}{ Males } & \multicolumn{2}{|c|}{ Females } & \multicolumn{2}{|c|}{ Males } & \multicolumn{2}{|c|}{ Females } \\
\hline & Actuals & $\begin{array}{c}\text { Crude } \\
\text { rate }\end{array}$ & Actuals & $\begin{array}{l}\text { Crude } \\
\text { rate }\end{array}$ & Actuals & $\begin{array}{l}\text { Crude } \\
\text { rate }\end{array}$ & Actuals & $\begin{array}{l}\text { Crude } \\
\text { rate }\end{array}$ \\
\hline I9I I & $\mathrm{I}, 763$ & IOI & 438 & 23 & $53^{\circ}$ & 30 & 105 & 6 \\
\hline $19 I_{4}$ & $\mathrm{I}, 83 \mathrm{I}$ & 102 & 434 & 23 & 600 & 34 & 120 & 6 \\
\hline 1917 & $\mathrm{I}, 94^{\circ}$ & I 26 & 425 & 22 & $64 \mathrm{I}$ & 45 & II 6 & 6 \\
\hline 1920 & $I, 270$ & $7^{\mathrm{I}}$ & 234 & 12 & $5^{22}$ & 29 & 87 & 4 \\
\hline 1926 & $I, I 6 I$ & 62 & 277 & I4 & 630 & 34 & II 7 & 6 \\
\hline I93I & 945 & 49 & 259 & 12 & 557 & 29 & II 4 & 5 \\
\hline 1932 & 864 & 45 & 236 & I I & 634 & 33 & I 44 & 7 \\
\hline I933 & $77 \mathrm{I}$ & 40 & 239 & I I & 592 & $3 \mathbf{I}$ & I4I & 7 \\
\hline 1934 & 788 & $4^{I}$ & 224 & I I & 496 & 26 & I07 & 5 \\
\hline I935 & 725 & 37 & 240 & I I & 553 & 28 & I 18 & 6 \\
\hline
\end{tabular}

TABLE J.-ANEURYSM.

Deaths and Crude Annual Death Rates per million living in different age groups.-Information extracted from the Registrar-General's Statistical Reviews.

\begin{tabular}{|c|c|c|c|c|c|c|c|c|c|c|}
\hline \multirow{2}{*}{ Year } & \multicolumn{2}{|c|}{$0-30$} & \multicolumn{2}{|c|}{$30-60$} & \multicolumn{2}{|c|}{$60-$} & \multicolumn{2}{|c|}{ All ages } & \multicolumn{2}{|c|}{ Crude rates } \\
\hline & M. & F. & M. & F. & M. & F. & M. & F. & M. & F. \\
\hline I9I I & 26 & 5 & 671 & 105 & 238 & I I 5 & 935 & 225 & 53 & I 2 \\
\hline 1915 & 14 & 6 & 600 & 103 & 282 & 136 & 896 & 245 & $5^{2}$ & I3 \\
\hline 1921 & 6 & 5 & 518 & 82 & 263 & II 8 & 787 & 205 & 44 & Io \\
\hline 1925 & 9 & I I & 479 & 104 & $34 \mathrm{I}$ & I 21 & 829 & 236 & 45 & 12 \\
\hline 1926 & I5 & 4 & $43^{6}$ & Ior & 326 & 140 & 777 & 245 & $4^{2}$ & 12 \\
\hline I93I & 43 & 13 & 462 & 126 & 484 & 186 & 989 & 325 & $5^{2}$ & I6 \\
\hline 1932 & 37 & 23 & 460 & 122 & $46 \mathrm{I}$ & I9I & $95^{8}$ & 336 & 50 & 16 \\
\hline I933 & 40 & 33 & 447 & 158 & 444 & 223 & $93 I$ & 4I 4 & 48 & 20 \\
\hline I934 & 42 & 28 & $44^{2}$ & I53 & 500 & 250 & 984 & $43 I$ & $5 \mathrm{I}$ & 20 \\
\hline 1935 & $5^{2}$ & 36 & $43^{8}$ & I 73 & 492 & 250 & 982 & 459 & 50 & 22 \\
\hline
\end{tabular}




\section{BRITISH JOURNAL OF VENEREAL DISEASES}

TABLE K.-ANeurysm.

Death Rates per million population in different age groups.-Calculated from figures given in the RegistrarGeneral's Statistical Reviews and the Census Reports for I9II, I92I and I93I.

\begin{tabular}{|c|c|c|c|c|c|c|c|c|c|}
\hline \multicolumn{2}{|c|}{ Rates calculated on } & \multicolumn{6}{|c|}{ Age periods } & \multirow{2}{*}{\multicolumn{2}{|c|}{ All ages }} \\
\hline \multirow{2}{*}{ Deaths in } & \multirow{2}{*}{$\begin{array}{l}\text { Census } \\
\text { popula- } \\
\text { tion in }\end{array}$} & \multicolumn{2}{|c|}{$0-30$} & \multicolumn{2}{|c|}{$30-60$} & \multicolumn{2}{|l|}{$60-$} & & \\
\hline & & M. & F. & M. & F. & M. & F. & M. & F. \\
\hline I9II • • & I9I I & $\begin{array}{c}2 \cdot 6 \\
(58 \cdot 1 \\
\text { per } \\
\text { cent. })\end{array}$ & $\begin{array}{r}0 \cdot 5 \\
(56 \cdot 4 \\
\text { per } \\
\text { cent. })\end{array}$ & $\begin{array}{c}\text { I I I } \cdot 6 \\
\left(34^{\circ} 5\right. \\
\text { per } \\
\text { cent. })\end{array}$ & $\begin{array}{c}16 \cdot 1 \\
(34 \cdot 9 \\
\text { per } \\
\text { cent. })\end{array}$ & $\begin{array}{c}185.1 \\
(7 \cdot 4 \\
\text { per } \\
\text { cent.) }\end{array}$ & $\begin{array}{c}7 \mathrm{I} \cdot 3 \\
(8 \cdot 7 \\
\text { per } \\
\text { cent. })\end{array}$ & $53 \cdot 6$ & I $2 \cdot I$ \\
\hline $\begin{array}{l}1909 \text { to } 1913 \\
\text { (Average p.a.) }\end{array}$ & ", & 3.6 & 0.8 & I $12 \cdot 9$ & $\mathrm{I} 7 \cdot 5$ & $167 \cdot 0$ & $59 \cdot 4$ & $53 \cdot 4$ & II $\cdot 2$ \\
\hline 1915 & ", & $I \cdot 4$ & 0.6 & $99 \cdot 7$ & I $5 \cdot 8$ & $219 \cdot 3$ & $84 \cdot 4$ & $5 I \cdot 4$ & $13 \cdot 2$ \\
\hline I92I . & I92 I & $\begin{array}{c}0 \cdot 6 \\
\left(54^{\cdot} 2\right. \\
\text { per } \\
\text { cent. })\end{array}$ & $\begin{array}{c}\mathbf{0 . 5} \\
\left(5^{2} \cdot \mathrm{I}\right. \\
\text { per } \\
\text { cent. })\end{array}$ & $\begin{array}{c}77^{\circ} \cdot 4 \\
\left(37^{\circ} 0\right. \\
\text { per } \\
\text { cent. })\end{array}$ & $\begin{array}{c}\text { I0.9 } \\
(37 \cdot 9 \\
\text { per } \\
\text { cent. })\end{array}$ & $\begin{array}{c}\mathrm{I} 66 \cdot 3 \\
(8 \cdot 8 \\
\text { per } \\
\text { cent. })\end{array}$ & $\begin{array}{c}59 \cdot 3 \\
(\text { Io.o } \\
\text { per } \\
\text { cent.) }\end{array}$ & 43.5 & $10 \cdot 3$ \\
\hline $\begin{array}{l}\text { I919 to } 1923 \\
\text { (Average p.a.) }\end{array}$ & ," & 0.9 & 0.4 & $74 \cdot 4$ & $\mathrm{II} \cdot 3$ & $170 \cdot 1$ & $55 \cdot 8$ & $42 \cdot 9$ & $10 \cdot 1$ \\
\hline $1925 \cdot$ & ", & $0 \cdot 9$ & I $\cdot \mathbf{I}$ & $7 I \cdot 5$ & 13.9 & $215 \cdot 7$ & $60 \cdot 8$ & $45 \cdot 9$ & II $\cdot 9$ \\
\hline 1931. & I93 I & $\begin{array}{c}4 \cdot 4 \\
(5 \mathrm{I} \cdot 5 \\
\text { per } \\
\text { cent. })\end{array}$ & $\begin{array}{c}1 \cdot 3 \\
(47 \cdot 8 \\
\text { per } \\
\text { cent. })\end{array}$ & $\begin{array}{c}63 \cdot 8 \\
(37 \cdot 7 \\
\text { per } \\
\text { cent.) }\end{array}$ & $\begin{array}{c}15 \cdot 2 \\
(39 \cdot 8 \\
\text { per } \\
\text { cent. })\end{array}$ & $\begin{array}{c}236 \cdot 0 \\
(10 \cdot 8 \\
\text { per } \\
\text { cent. })\end{array}$ & $\begin{array}{c}72 \cdot 4 \\
(\mathrm{r} 2 \cdot 3 \\
\text { per } \\
\text { cent. })\end{array}$ & $5 I \cdot 7$ & I5.6 \\
\hline $\begin{array}{l}\text { I929 to I933 } \\
\text { (Average p.a.) }\end{array}$ & ", & 3.5 & $1 \cdot 9$ & $64 \cdot 3$ & 15.9 & $217 \cdot 8$ & $72 \cdot 9$ & $50 \cdot 5$ & $16 \cdot 3$ \\
\hline I935 & ", & $5 \cdot 3$ & $3 \cdot 6$ & $60 \cdot 5$ & $20 \cdot 9$ & $239 \cdot 9$ & $97 \cdot 3$ & $5 \mathrm{I} \cdot 3$ & $22 \cdot 0$ \\
\hline
\end{tabular}

The figures in brackets represent the percentages of the population in the respective age groups. 


\section{VENEREAL DISEASES SCHEMES}

TABLE L.-Examinations and Pathological Specimens.(a) In Approved Laboratories, (b) In V.D. Treatment Centres.

\begin{tabular}{|c|c|c|c|c|c|c|c|c|}
\hline & \multicolumn{4}{|c|}{ For V.D. Treatment Centres } & \multicolumn{4}{|c|}{$\begin{array}{l}\text { For practitioners and institutions other } \\
\text { than V.D. Treatment Centres }\end{array}$} \\
\hline & 1932 & 1933 & I934 & 1935 & 1932 & 1933 & I934 & 1935 \\
\hline $\begin{array}{r}\text { Microscopical- } \\
\text { For } S . \text { pallida } \\
(a) \\
(b)\end{array}$ & $\begin{array}{l}2,105 \\
4,734 \\
\end{array}$ & $\begin{array}{l}\mathrm{I}, 789 \\
4,698 \\
\end{array}$ & $\begin{array}{l}1,549 \\
4,078\end{array}$ & $\begin{array}{l}\mathrm{I}, 8 \mathrm{I} 5 \\
4,75 \mathrm{I} \\
\end{array}$ & $3^{321}$ & $\stackrel{225}{-}^{225}$ & $-^{\text {I93 }}$ & $\stackrel{1}{135}^{-}$ \\
\hline Totals & 6,839 & 6,487 & 5,627 & 6,566 & $32 \mathrm{I}$ & 225 & I93 & 135 \\
\hline $\begin{array}{r}\text { For gonococci } \\
\qquad(a) \\
(b)\end{array}$ & $\begin{array}{r}139,207 \\
75,368 \\
\end{array}$ & $\begin{array}{r}131,463 \\
70,457 \\
\end{array}$ & $\begin{array}{r}165,896 \\
67,47 \mathrm{I} \\
\end{array}$ & $\begin{array}{r}\mathrm{I} 66,978 \\
75,2 \text { I } 9 \\
\end{array}$ & 23,170 & 23,927 & 27,033 & $\stackrel{26,423}{-}$ \\
\hline Totals & $2 \mathrm{I} 4,575$ & 201,920 & 233,367 & 242,197 & 23,170 & 23,927 & 27,033 & 26,423 \\
\hline $\begin{array}{l}\text { Serum tests }(a) \\
\text { For syphilis- } \\
\text { Wassermann } \\
\text { Others } \\
\text { For gonorrhœa }\end{array}$ & $\begin{array}{r}\text { I } 3,978 \\
30,3 \text { I } 3 \\
23,353 \\
\end{array}$ & $\begin{array}{r}\text { I } 30, \text { I } 26 \\
36,578 \\
28,986 \\
\end{array}$ & $\begin{array}{r}134,324 \\
39,830 \\
36,386\end{array}$ & $\begin{array}{r}134,072 \\
* 44,459 \\
42,62 I\end{array}$ & $\begin{array}{r}96,043 \\
16,342 \\
2,350\end{array}$ & $\begin{array}{r}98,325 \\
16,193 \\
3,578\end{array}$ & $\begin{array}{r}103,983 \\
19,2 \text { I I } \\
4,004\end{array}$ & $\begin{array}{r}\text { I } 12,520 \\
* \text { I } 8,267 \\
6,136\end{array}$ \\
\hline $\begin{array}{l}\text { Tests of cerebro- } \\
\text { spinal fluid }(a) \\
\text { Cultures }(a) \\
\text { Others not clas- } \\
\text { sified above }(a)\end{array}$ & $\begin{array}{r}1,236 \\
24,821 \\
22,608\end{array}$ & $\begin{array}{r}\text { I,42 I } \\
36,797 \\
\text { I I,3 I } 8\end{array}$ & $\begin{array}{r}\mathrm{I}, 288 \\
5 \mathrm{I}, 926 \\
8,234\end{array}$ & $\begin{array}{r}1,513 \\
61,401 \\
5,703\end{array}$ & $\begin{array}{r}5,010 \\
2,128 \\
396\end{array}$ & $\begin{array}{r}4,384 \\
3,518 \\
506\end{array}$ & $\begin{array}{r}4,400 \\
5,122 \\
797 \\
\end{array}$ & $\begin{array}{l}4,736 \\
4,598 \\
1,059\end{array}$ \\
\hline $\begin{array}{l}\text { Totals all } \\
\text { examinations }\end{array}$ & 447,723 & 453,633 & 510,982 & 538,532 & 145,760 & I 50,656 & 164,743 & I 73,874 \\
\hline
\end{tabular}

* Kahn, Meinicke, Priestley, Sigma, Vernes, practically always applied in addition to the Wassermann. 